\title{
Aspectos neuroquímicos: o papel da serotonina no TOC
}

\author{
Frederico G Graeff
}

Departamento de Neurologia, Psiquiatria e Psicologia Médica da Faculdade de Medicina de Ribeirão Preto, Universidade de São Paulo. Ribeirão Preto, SP, Brasil

\begin{abstract}
The therapeutic action of selective serotonin (5-HT) reuptake inhibitors (SSRIs) in obsessive-compulsive disorder (OCD) points to the role of 5-HT in this condition. Functional neuroimaging studies showed hyperactivity of the nucleus caudatum in OCD patients, which disappears following treatment with either SSRIs or cognitive behavior therapy. Pharmacological results indicate hypersensitivity of the 5-HT $T_{1 D}$ receptor subtype in OCD, similarly reversed by chronic administration of SSRIs. Neurochemical data show that these receptors are selectively concentrated in the striatum, and are localized in 5-HT terminals, where they inhibit 5-HT release by the nerve impulse. Since 5-HT reduces the activity of post-synaptic neurons in the striatum, it has been suggested that the hypersensitivity of 5-HT ${ }_{1 D}$ receptors contribute to the genesis of OCD symptoms.
\end{abstract}

Keywords Obsessive-compulsive disorder. Receptors. Serotonin.

\section{Introdução}

A observação de que inibidores da recaptação de serotonina (5-HT) melhoram o transtorno obsessivo-compulsivo (TOC) - vide Tratamento farmacológico - foi a primeira indicação de que a 5-HT poderia exercer importante papel nesse transtorno de ansiedade. $O$ primeiro medicamento desse tipo a ser empregado foi a clorimipramina ou clomipramina, cuja eficácia foi comprovada em estudos abertos e duplo-cegos. ${ }^{1}$ A clomipramina tem grande afinidade pelo sítio de recaptação de 5-HT e baixa afinidade pelo sítio correspondente da noradrenalina (NA). Porém, seu metabólito - desmetilclorimipramina - inibe predominantemente a recaptação de NA. Assim sendo, a clomipramina não pode ser encarada como verdadeiro inibidor seletivo de recaptação de serotonina (ISRS), quando administrada cronicamente.

Contudo, outras evidências vieram fortalecer a hipótese da mediação serotonérgica da ação farmacológica anti-TOC. A primeira foi a verificação de que a imipramina é bem menos eficaz que a clomipramina no TOC. ${ }^{2}$ Essa diferença contrasta com a equivalência da ação terapêutica dos dois medicamentos no transtorno depressivo unipolar e na moderada vantagem da clomipramina sobre a imipramina no transtorno do pânico. Como a imipramina inibe igualmente a recaptação de 5-HT e de NA, sua ineficácia no TOC indica que a inibição da recaptação da NA é desnecessária ou mesmo contraproducente. A segunda evidência veio à luz com a introdução dos ISRS, como a fluoxetina, fluvoxamina e sertralina, cujos metabólitos não interferem com a recaptação de NA. Verificou-se que tais compostos também eram eficazes no tratamento do TOC. ${ }^{2}$

Dessa forma, o conceito de que a 5-HT é crítica para ação anti-TOC ficou bem estabelecido. A questão seguinte é: onde atuam esses agentes terapêuticos? A resposta a essa pergunta passa pela fisiopatogenia do TOC e conduz ao tema central deste artigo, que é o papel da 5-HT no TOC.

\section{Fisiopatogenia do TOC}

A teoria mais aceita da fisiopatogenia do TOC foi formulada por Judith Rapoport, adotando a perspectiva da psicologia evolutiva. Baseando-se em Charles Darwin, essa orientação teórica postula que as características comportamentais dos animais estão sujeitas à seleção natural da mesma forma que as anatômicas e fisiológicas. Constatando que as compulsões mais freqüentes são as de limpeza (cleaning) e de conferir se portas e janelas estão fechadas (checking), Rapoport levantou a hipótese de que tais manifestações seriam exageros de rotinas de autolimpeza (self grooming) e de conferir demarcações territoriais, respectivamente. Estas foram adquiridas por numerosas espécies devido ao valor adaptativo para prevenir doenças e garantir espaço vital necessário para alimentação e reprodução. Na expressão da autora, a compulsão de lavar repetidamente as mãos nada mais seria do que um grooming gone wild, ou seja, uma exacerbação do comportamento de autolimpeza. $^{3}$

Essa concepção sobre a gênese do TOC levou à busca de comportamentos com características compulsivas em animais, sendo que dois deles chamaram logo a atenção. O primeiro é o hábito dos cães, sobretudo os da raça Labrador, de lamber excessivamente as patas, o que acarreta ferimentos graves. Essa condição é denominada dermatite acral. O segundo é o comportamento, que ocorre em certas aves submetidas ao cativeiro, de remover incessantemente as penas com o bico. Se tais comportamentos guardam homologia com 
o transtorno compulsivo, isto é, compartilham do mesmo substrato neurobiológico, deveriam ser igualmente suscetíveis aos ISRS. Essa predição foi confirmada em ensaios farmacológicos controlados, resultando em tratamento de escolha para essas afecções. Provavelmente este é o único exemplo de tratamento veterinário que derivou de uma teoria sobre a fisiopatogenia de um transtorno psiquiátrico do ser humano.

\section{Substrato neuroanatômico}

Outra contribuição da teoria de Rapoport sobre o TOC foi dirigir a pesquisa sobre o substrato neuroanatômico do TOC para os núcleos da base. Isto por que o estriado é estrutura crítica para a organização de comportamentos inatos, como as rotinas de autolimpeza e de conferir limites territoriais. De fato, técnicas de neuroimagens funcionais do cérebro apontam para disfunção do núcleo caudado, somado ao córtex órbito-frontal e ao tálamo no TOC (veja Valente \& Busatto-Filho neste número).

Particularmente relevante para a presente análise são os trabalhos realizados por Baxter et $\mathrm{al}^{4}$ na Califórnia. Utilizando varredura com tomografia de emissão de pósitrons (PET scan), esses pesquisadores descreveram uma hiperativação das três estruturas enumeradas acima em pacientes com TOC. Esse achado é sugestivo de que uma reverberação do circuito caudato-tálamo-frontal é responsável pelas manifestações obsessivo-compulsivas. Apoiando essa hipótese, resultados obtidos no mesmo laboratório mostraram que os dois procedimentos terapêuticos mais eficazes - medicação com ISRS, no caso, a fluoxetina, e terapia cognitivo-comportamental - eliminavam a mencionada hiperativação identificada pelo PET. ${ }^{4}$ Sem esquecer que o maior impacto desses achados foi o de documentar, pela primeira vez, uma alteração neurofisiológica determinada por uma modalidade de psicoterapia, o fato de um ISRS modular a atividade do estriado remete novamente a 5-HT e dá uma pista valiosa sobre qual é o sistema serotonérgico e o tipo de receptor mais provavelmente envolvidos no TOC.

\section{Sistema serotonérgico mesoestriatal e receptores $5-\mathbf{H T}_{1 \mathrm{D}}$}

Sabe-se que a inervação serotonérgica do prosencéfalo provém de dois núcleos situados no mesencéfalo: o núcleo mediano da rafe (NMR) e o núcleo dorsal da rafe (NDR). Enquanto as fibras originárias no NMR projetam-se sobretudo em estruturas límbicas, aquelas originárias no NDR inervam predominantemente os núcleos da base e o neocórtex. ${ }^{5}$ Em face das evidências anatômicas e funcionais acima discutidas, podese deduzir que a via serotonérgica que parte do NDR e projetase no caudato é a candidata mais provável para participar da fisiopatogenia do TOC.

Quanto aos receptores de 5-HT, sabe-se que se subdividem em diversos tipos e subtipos, cuja localização celular e anatômica, bem como o papel funcional, são igualmente diferentes (para uma revisão, ver Graeff ${ }^{6}$ ). Chama particularmente a atenção o fato de os receptores do subtipo 5-HT ${ }_{1 \mathrm{~B} / 1 \mathrm{D}}$ estarem seletivamente concentrados no estriado. A dupla denominação 1B/1D advém da diversidade no perfil farmacológico. Por exemplo, o propranolol bloqueia o receptor 5$\mathrm{HT}_{1 \mathrm{~B}}$, mas não o $5-\mathrm{HT}_{1 \mathrm{D}}$. Os primeiros ocorrem em certas espécies, como o rato, e o segundo, em outras, inclusive no ser humano. No mais, assemelham-se em tudo, particularmente no que diz respeito à localização e função. Trata-se de receptores pré-sinápticos, situados na membrana das varicosidades das fibras nervosas terminais, de onde a 5-HT é liberada por ação do impulso nervoso. A estimulação dos receptores 5-HT ${ }_{1 \mathrm{~B} 1 \mathrm{D}}$ diminui a quantidade de 5-HT assim liberada. Portanto, tais receptores têm papel regulador sobre a liberação do neurotransmissor, limitando-a quando as concentrações da amina na fenda sináptica atingem níveis elevados. Trata-se, portanto, do mecanismo bem conhecido de retroalimentação negativa (negative feedback).

\section{Hipótese sobre o papel da 5-HT no TOC}

Além da disposição anatômica, a idéia de que receptores 5-HT ${ }_{1 \mathrm{D}}$ participam da fisiopatogenia do TOC ganhou importante apoio farmacológico com a verificação de que o agonista 5-HT ${ }_{1 \mathrm{D}}$ seletivo, sumatriptan, agrava os sintomas de pacientes com TOC. ${ }^{7}$ Essa evidência soma-se a resultados anteriores com o agente menos seletivo metaclorofenilpiperazina (mCPP). Nesse caso, verificou-se também que o tratamento crônico com clomipramina abole o efeito agravante do $\mathrm{mCPP} .{ }^{1}$ Como os ISRS reduzem a sensibilidade do receptor $5-\mathrm{HT}_{1 \mathrm{~B} / 1 \mathrm{D}}$ em relação aos agonistas após uso prolongado, levantou-se a hipótese de que esse subtipo de receptor estaria supersensível no TOC. ${ }^{1,7}$ Como decorrência, haveria menor liberação de 5-HT na via serotonérgica mesoestriatal, com redução da concentração sináptica de 5HT no estriado, resultando em ativação do circuito caudatotálamo-frontal responsável pelas manifestações do TOC. Com efeito, um estudo com tomografia computadorizada de emissão de fóton singular (Spect) mostrou maior hiperatividade dessas estruturas durante o agravamento sintomático induzido pelo sumatriptan. ${ }^{8}$

\section{Conclusão}

Pode-se concluir que há evidências sugestivas de que a supersensibilidade de receptores pré-sinápticos do tipo 5$\mathrm{HT}^{\mathrm{ID}}$, localizados na via serotonérgica mesoestriatal, seja responsável pela desinibição do circuito caudato-tálamo-cortical, gerador dos sintomas compulsivos do TOC. A administração crônica dos ISRS diminuiria a sensibilidade dos mesmos receptores, melhorando o quadro clínico.

Este trabalho foi financiado pela Fundação de Amparo ao Ensino, Pesquisa e Assistência (Faepa) do Hospital das Clínicas da Faculdade de Medicina de Ribeirão Preto. 


\section{Referências}

1. Zohar J, Insel TR, Zohar-Kadouch RC, Murphy DL. Serotonergic responsivity in obsessive-compulsive disorder: effects of clomipramine treatment. Arch Gen Psychiatry 1988;45:167-72.

2. Zohar J, Zohar-Kadouch RC, Kindler S. Current concepts in the pharmacological treatment of obsessive-compulsive disorder. Drugs 1992;43:210-8.

3. Rapoport JL. Recent advances in obsessive-compulsive disorder. Neuropsychopharmacology 1991;5:1-10.

4. Baxter IR, Schwartz JM, Bergman KS, Szuba MP, Guze BH, Mazziota JC et al. Caudate glucose metabolic rate changes with both drug and behavior therapy for obsessive-compulsive disorder. Arch Gen Psychiatry 1992;49:681-9.
5. Azmitia EC, Segal, M. An autodiographic analysis of the differential ascending projections of the dorsal and median raphe nuclei in the rat. J Comp Neurol 1978:179:641-88.

6. Graeff FG. Serotonergic systems. Psychiatr Clin N Am 1997;20:723-39.

7. Dolberg OT, Iancu I, Sasson Y, Zohar J. The pathogenesis and treatment of obsessive compulsive disorder. Clin Neuropharmacol 1996;19:129-47.

8. Stein DJ, Van Heerden B, Wessels CJ, Van Kradenburg J, Warwick J, Wasserman HJ. Single photon emission computed tomography of the brain with Tc-99 m HMPAO during sumatriptan challenge in obsessive-compulsive disorder: investigating the functional role of the serotonin auto-receptor. Prog Neuro-Psychopharmacol Biol

\section{Correspondência: Frederico G Graeff}

Av. 9 de julho, 980 - 14025-000 Ribeirão Preto, SP, Brasil

Tel.: (0xx16) 636-7325-Fax: (0xx16) 635 0713 - E-mail: fgraeff@ keynet.com.br 